\title{
Imaging of acute cholecystitis and cholecystitis- associated complications in the emergency setting
}

\author{
Ashish Chawla' ${ }^{1}$ DABR, Jerome Irai Bosco ${ }^{1}$, MD, Tze Chwan Lim ${ }^{1}$, FRCR, Sivasubramanian Srinivasan ${ }^{1}, \mathrm{FRCR}$, \\ Hui Seong $\underline{T e h}^{1}$, FRCR, Jagadish Narayana Shenoy ${ }^{1}$, FRCR, FRANZCR
}

\begin{abstract}
Acute cholecystitis is a common cause of right upper quadrant pain in patients presenting at the emergency department. Early diagnosis and recognition of associated complications, though challenging, are essential for timely management. Imaging studies, including ultrasonography, computed tomography and magnetic resonance imaging, are increasingly utilised for the evaluation of suspected cases of cholecystitis. These investigations help in diagnosis, identification of complications and surgical planning. Imaging features of acute cholecystitis have been described in the literature and are variable, depending on the stage of inflammation. This article discusses the spectrum of cholecystitisassociated complications and their imaging manifestations. We also suggest a checklist for the prompt and accurate identification of complications in acute cholecystitis.
\end{abstract}

Keywords: cholecystitis, CT, emphysematous cholecystitis, gallstone ileus, Mirizzi syndrome

\section{INTRODUCTION}

Acute cholecystitis is an acute inflammatory condition of the gallbladder; $95 \%$ of cases of acute cholecystitis are due to an obstructing calculus in the gallbladder neck or cystic duct. ${ }^{(1)}$ Obstruction of the cystic duct results in an overdistension of the gallbladder and a rise in intraluminal pressure. This increased pressure, along with cholesterol-supersaturated bile, triggers an acute inflammatory response. Gallstones contribute to the inflammatory response by stimulating prostaglandins $\mathrm{I}_{2}$ and $\mathrm{E}_{2} \cdot{ }^{(2}$ Secondary bacterial infection is present in $20 \%$ of cases of acute cholecystitis. Mural ischaemia resulting from the increased intraluminal pressure may also contribute to complications such as gangrenous cholecystitis and perforation. ${ }^{(3)}$ Pathologically, there are three stages of inflammatory disease: (a) oedematous cholecystitis; (b) necrotising cholecystitis; and (c) suppurative cholecystitis. ${ }^{(1)}$

Due to the wide availability of computed tomography (CT) scanners in emergency departments, increasing numbers of patients undergo CT examinations for suspected acute cholecystitis. Ultrasonography (US) remains the preferred initial imaging modality for the evaluation of suspected acute calculous cholecystitis due to its relatively low cost, easy accessibility, short examination duration and lack of ionising radiation (Fig. 1).(4) The distinct advantages of US over other imaging techniques are its high sensitivity and specificity in detecting gallstones, and its ability to elicit 'Murphy's sign' using the ultrasound transducer. ${ }^{(4,5)}$ However, US has limited value in the evaluation of underlying complications of acute cholecystitis. Evaluation of such complications may require cross-sectional imaging techniques, namely $\mathrm{CT}$ or magnetic resonance (MR) imaging, for accurate localisation and surgical planning. CT and MR imaging can also be used to evaluate or exclude other pathologies that can present with right upper quadrant pain.

\section{CT OF ACUTE CHOLECYSTITIS AND ASSOCIATED COMPLICATIONS}

CT features of uncomplicated acute cholecystitis include a combination of overdistended gallbladder, mural thickening, mural enhancement, pericholecystic fat stranding and pericholecystic fluid. ${ }^{(6,7)}$ Characteristically, there is an enhancement rim in the adjacent liver. ${ }^{\left({ }^{(8)}\right.}$ Classically, a calculus can be seen impacted in the gallbladder neck or cystic duct (Fig. 2). It is well known that $\mathrm{CT}$ has a relatively low sensitivity in detecting gallstones due to the variable composition of the stones. Even larger isodense gallstones may not be visible on $\mathrm{CT} .{ }^{(9)} \mathrm{US}$ is more sensitive in detecting cholelithiasis and is useful in identifying the offending gallstone in some cases. Gallbladder mural thickening is the most common but the least specific finding and may be seen in a variety of other conditions, such as hepatitis, hypoproteinaemia, heart failure and acute pyelonephritis..$^{(6,10,11)}$

Gangrenous cholecystitis results from the downhill course of an episode of acute cholecystitis and occurs in up to $39 \%$ of patients with acute calculous cholecystitis. ${ }^{(12)}$ It is associated with higher morbidity and mortality rates than uncomplicated acute cholecystitis. Elderly patients, and patients with a history of diabetes mellitus and white blood cell count $>15,000$ cells $/ \mathrm{mL}$ are at an increased risk of having gangrenous changes at presentation. ${ }^{(12)}$ In addition to the typical imaging features of cholecystitis, CT findings of poorly enhancing walls, intraluminal membranes, striated and reduced mural enhancement, focal mural defects and pericholecystic abscesses have been described in cases of gangrenous cholecystitis, with specificity close to $90 \%$ (Figs. 3 \& 4). ${ }^{(13)}$ Based on our experience, it is important to evaluate the gallbladder wall for any presence of a focal bulge, which usually corresponds pathologically to a mural abscess (Fig. 5). If left untreated, these abscesses may increase in size and number, eventually resulting in a perforated gallbladder

${ }^{1}$ Department of Diagnostic Radiology, Khoo Teck Puat Hospital, Singapore

Correspondence: Dr Ashish Chawla, Consultant, Department of Diagnostic Radiology, Khoo Teck Puat Hospital, 90 Yishun Central, Singapore 768828. ashchawla@gmail.com 

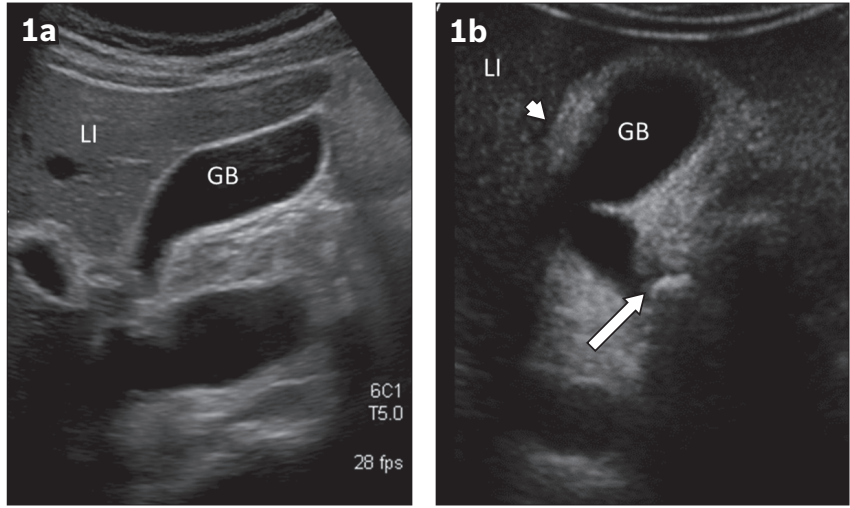

Fig. 1 Oblique coronal US images show (a) a normal gallbladder (GB); and (b) a thickened GB wall and thin layer of pericholecystic fluid (arrowhead), with an impacted calculus in the neck of the GB (arrow) in a patient with acute cholecystitis. LI: liver
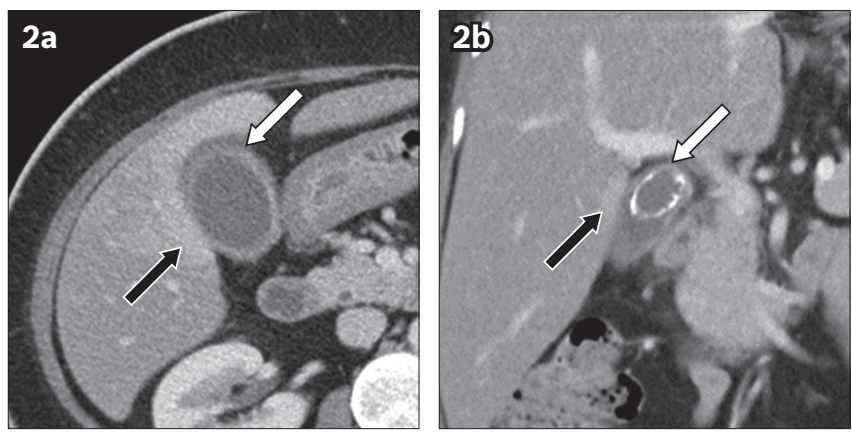

Fig. 2 CT images of classical acute calculous cholecystitis show (a) a thickened enhancing gallbladder wall, pericholecystic fat stranding (white arrow) and reactive hyperaemia in the adjacent liver (black arrow) in the axial plane; and (b) a large calculus in the neck of the gallbladder (white arrow) and reactive hyperaemia (black arrow) in the adjacent liver in the coronal plane.

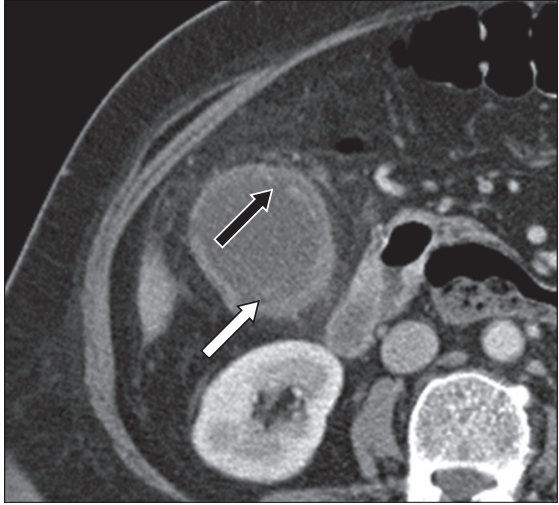

Fig. 3 Axial CT image of acute gangrenous cholecystitis shows thickened walls and focal defects (black arrow) in an enhancing mucosa with hyperdense sloughed mucosa floating in the dependent gallbladder (white arrow). Note the 'sunburst' pattern of pericholecystic fat stranding.
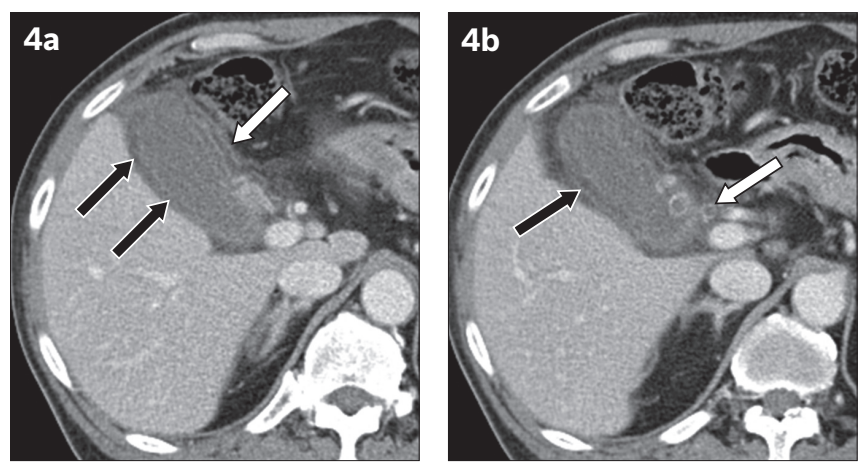

Fig. 4 Axial CT images of acute gangrenous cholecystitis show (a) a poorly enhancing gallbladder wall (black arrows) and a striated appearance of the medial wall (white arrow); and (b) poorly enhancing walls (black arrow) and a calculus (white arrow) impacted in the neck of the gallbladder. Note the presence of a few other gallstones.
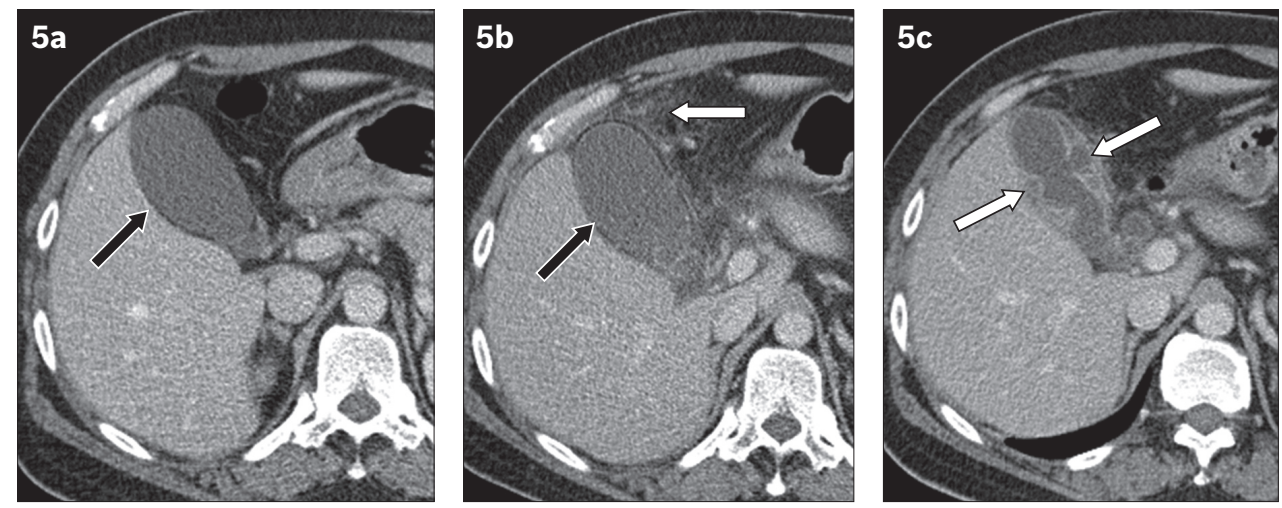

Fig. 5 Evolving gangrenous cholecystitis in a 34-year-old man presenting with right hypochondrial pain. (a) Axial CT image on the day of presentation shows poor enhancement of the gallbladder wall (black arrow). No gallstone or definite cholecystic fat stranding was identified, and the patient was kept on conservative management. (b) Axial CT image on Day 3 shows a poorly enhancing wall (black arrow) and pericholecystic fat stranding (white arrow). (c) Axial CT image on Day 10 shows intramural abscesses (white arrows), a sign of gangrenous cholecystitis. The patient underwent urgent cholecystectomy, which confirmed gangrenous cholecystitis with mucosal ulcers and mural abscesses.

(Fig. 6). The presence of a focal mural defect that is contiguous with pericholecystic fluid is an ominous sign and suggests perforation in the gallbladder, which can result in pericholecystic abscess, intrahepatic abscess (Fig. 7) or peritonitis, depending on the site of perforation. ${ }^{(14)} \mathrm{A}$ rapid increase in the amount of pericholecystic fluid, demonstrated in serial examinations (CT or US), is a reliable clue for diagnosing a perforated gallbladder (Fig. 8).
Emphysematous cholecystitis refers to the presence of gas in the gallbladder wall and is secondary to infections by gasforming organisms such as Clostridium welchi. Patients with diabetes mellitus are at a greater risk of developing this condition and may present initially with relatively milder symptoms. Plain radiography often shows the gallbladder wall being outlined by radiolucent gas (Fig. 9). CT is confirmatory, showing features of 

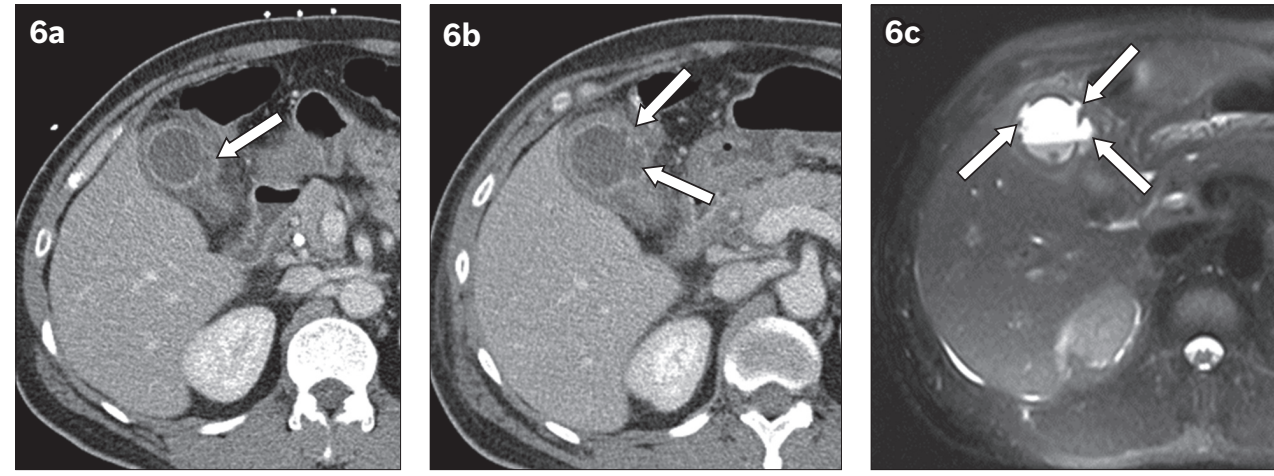

Fig. 6 Evolving gangrenous cholecystitis in a 55-year-old woman. (a) Axial CT image on the day of presentation shows pericholecystic inflammation and fluid with a focal bulge in the gallbladder wall (arrow). (b) CT image after one week of conservative treatment shows an increase in the size and number of bulges (arrows). (c) Axial T2-HASTE MR image one day after the second CT shows a further increase in the number of bulges (arrows). Laparotomy findings confirmed gangrenous cholecystitis with extensive inflammation around the gallbladder. Histopathological examination confirmed that these bulges corresponded to mucosal ulcers with mural abscesses.

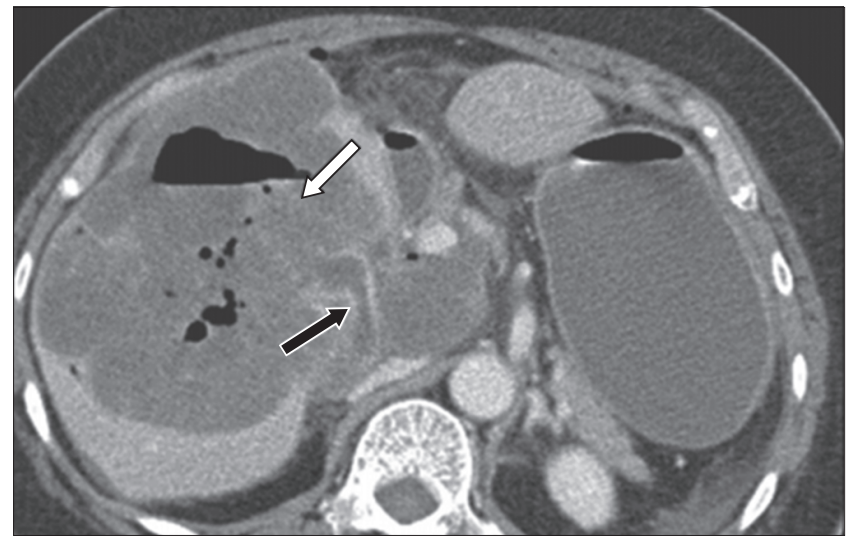

Fig. 7 Intrahepatic perforation of the gallbladder. Axial CT image depicts a large hepatic abscess (white arrow) with air pockets. Outline of the neck of the gallbladder is identified (black arrow), but the rest of the gallbladder is not seen as separate from the abscess.
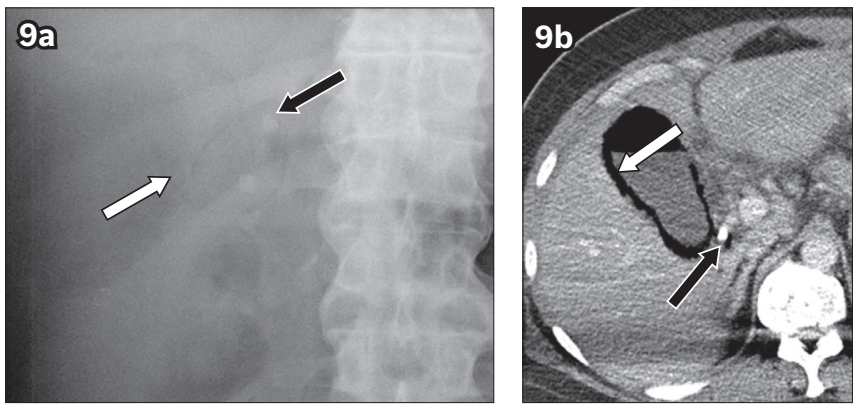

Fig. 9 Emphysematous cholecystitis. (a) Supine abdomen radiograph shows a pear-shaped curvilinear lucent line (white arrow) in the right upper quadrant with two radiopacities (black arrow) within it. (b) Axial CT image shows gas within the wall (white arrow) and in the lumen of the gallbladder. There is an impacted calculus in the gallbladder neck (black arrow).

cholecystitis along with intramural gas. ${ }^{(15)}$ The progression to perforated cholecystitis is more frequently seen in emphysematous cholecystitis than in uncomplicated cholecystitis.

Mirizzi syndrome results from an impacted gallstone in the gallbladder neck or cystic duct that causes extrinsic compression of the common hepatic duct. The result is biliary obstruction with dilatation of the intrahepatic bile ducts. A cholecystocholedochal fistula may form due to recurrent inflammation around the impacted gallstone in the cystic duct. Patients with this condition often present with abdominal pain,
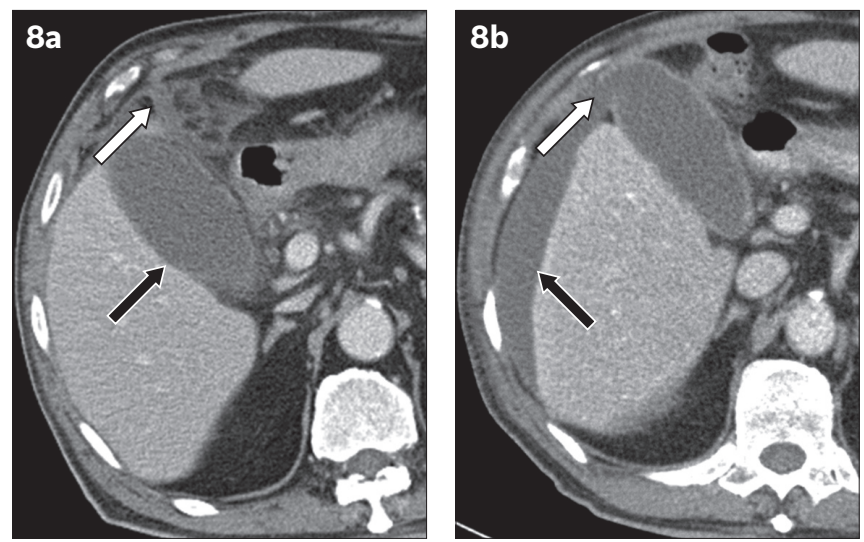

Fig. 8 Perforated cholecystitis in a 70-year-old woman presenting with abdominal pain at the emergency department. (a) Axial CT image shows a poorly enhancing gallbladder wall (black arrow), with pericholecystic fat stranding and minimal fluid (white arrow). (b) CT image after two days, due to worsening symptoms, shows a wall defect in the fundus of the gallbladder (white arrow) with a significant increase in perihepatic fluid (black arrow).
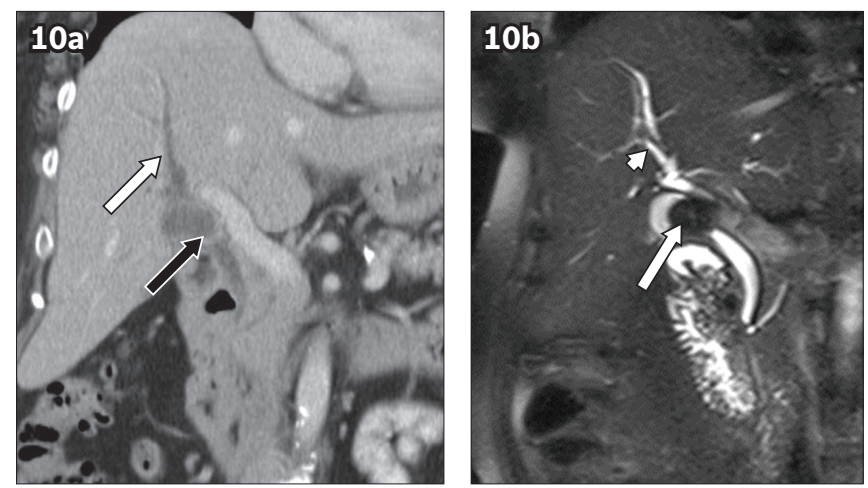

Fig. 10 Mirizzi syndrome in a 42-year-old woman presenting at the emergency department with fever and abdominal pain. (a) Coronal CT image shows a bulbous expansion of the neck of the gallbladder, due to a radiolucent calculus compressing the proximal hepatic duct (black arrow), with resultant dilatation of the central intrahepatic ducts (white arrow) but a normal distal duct. (b) Coronal MRCP image shows a large gallstone (arrow) compressing the proximal hepatic duct, with dilatation of the central intrahepatic ducts (arrowhead).

fever and jaundice, without any pathognomonic pattern, which therefore makes clinical diagnosis difficult. ${ }^{(16)}$ Preoperative diagnosis of Mirizzi syndrome is essential in planning surgeries, in view of the possibility of open cholecystectomy. CT can show 

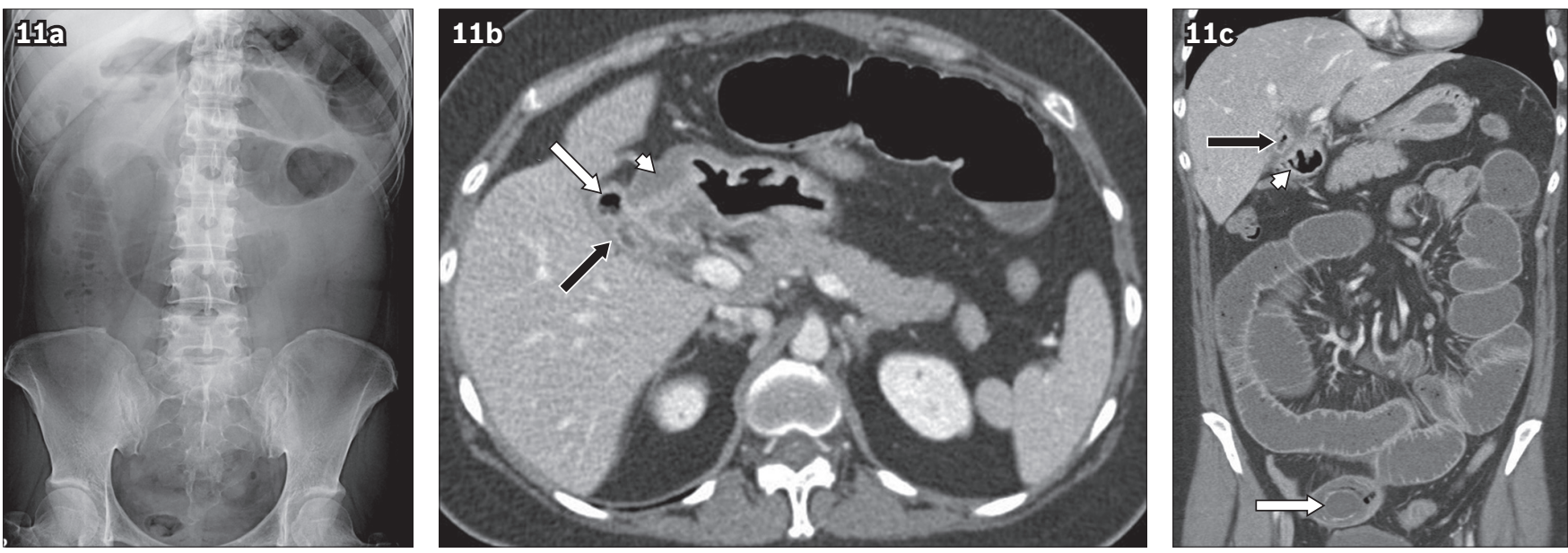

Fig. 11 Gallstone ileus in a 39-year-old man presenting at the emergency department with features of subacute bowel obstruction. (a) Supine abdominal radiograph shows dilatation of small bowel loops in the central abdomen. (b) Axial CT image shows a contracted gallbladder with a thickened wall (black arrow), with air in its lumen (white arrow). The gallbladder is inseparable from the first part of duodenum (arrowhead), and the duodenal wall is oedematous. (c) Coronal oblique CT image shows small bowel dilatation with a large peripherally calcified gallstone in the distal ileum (white arrow). The ileum distal to the gallstone is collapsed. Note the contracted, air-containing gallbladder (black arrow) abutting the proximal duodenum (arrowhead).

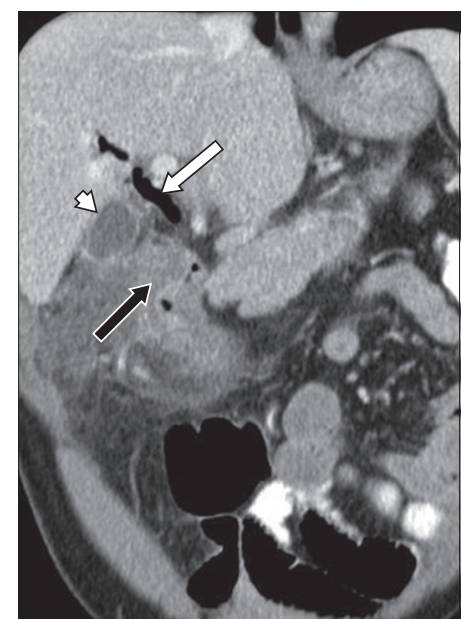

Fig. 12 Acute cholecystitis with cholecystoenteric fistula. Coronal oblique CT image shows a contracted gallbladder (arrowhead) with pericholecystic fluid and inflammation with pneumobilia (white arrow), abutting an oedematous proximal duodenum (black arrow). Laparotomy confirmed a fistulous communication between the gallbladder and the first part of the duodenum.

the dilated intrahepatic bile ducts with the common bile duct of normal calibre (Fig. 10). ${ }^{(17)}$ MR cholangiopancreatography (MRCP) provides more information about the exact location and cause of the obstruction. ${ }^{(18)}$

Gallstone ileus is a rare complication associated with a subclinical or milder episode of cholecystitis. Instead of right upper quadrant pain, the patient presents at the emergency department with signs and symptoms of bowel obstruction. ${ }^{(19)}$ Intestinal obstruction is the outcome of an impacted ectopic gallstone, usually in the distal ileum. These gallstones are usually larger than $2.5 \mathrm{~cm}$ and enter the gastrointestinal tract via a fistulous communication between the gallbladder and duodenum or, in rare occasions, between the gallbladder and stomach. ${ }^{(20)}$ Smaller gallstones may pass through the bowel loops asymptomatically without causing obstructions. CT, which can show Rigler's triad (small bowel obstruction, ectopic gallstone at point of transition and pneumobilia), is useful for accurate diagnosis of gallstone ileus. ${ }^{(21)}$ Based on our experience, the absence of pneumobilia with equivocal features of gallbladder inflammation can be misleading for the radiologist. In such cases, the typical appearance of gallstones in the dilated small bowel proximal to the transition point provides a clue for diagnosing gallstone ileus (Fig. 11). The presence of an obstructing gallstone should prompt a search for more stones with similar morphology within the gallbladder lumen as well as in the upstream dilated small bowel. Bouveret's syndrome is a rare condition that results from impaction of a discharged gallstone in the gastroduodenal junction, leading to gastric outlet obstruction. ${ }^{(22)} \mathrm{CT}$ allows direct visualisation of the biliary-enteric fistula in $12.5 \%$ of patients with gallstone ileus. ${ }^{(20)}$

Cholecystoenteric fistulas can develop in the setting of acute cholecystitis without a small bowel obstruction or ectopic gallstone. They can also develop due to trauma, peptic ulcer disease, inflammatory bowel disease and malignancy of the bowel and gallbladder. ${ }^{(23)}$ It has been postulated that recurrent cholecystitis leads to adhesions between the gallbladder and bowel, with subsequent fistula formation. ${ }^{(24)}$ Diagnosis of cholecystoenteric fistulas is important for surgeons but difficult for radiologists, particularly in the presence of a contracted gallbladder. We recommend that in the presence of unexplained pneumobilia, the relationship of the gallbladder with respect to the adjacent bowel should be evaluated. In demonstrating fistulas, multiplanar reconstructions are more helpful than conventional axial imaging (Fig. 12).

We have summarised the CT findings in various complications associated with acute cholecystitis (Table I). We also recommend a quick checklist that can be helpful in quick and accurate identification of complications (Table II).

\section{CONCLUSION}

Patients with acute cholecystitis, as well as those with associated complications, present at the emergency department with nonspecific symptoms, such as pain in the right upper quadrant. 
Table I. Summary of computed tomography findings in acute cholecystitis and associated complications.

\begin{tabular}{|c|c|}
\hline Diagnosis & Computed tomography findings \\
\hline $\begin{array}{l}\text { - Acute calculus } \\
\text { cholecystitis }\end{array}$ & $\begin{array}{l}\text { Gallstone in the gallbladder neck or cystic duct, thickened }(\geq 0.3 \mathrm{~cm}) \text { and enhancing wall, pericholecystic fat } \\
\text { stranding with or without pericholecystic fluid, reactive enhancement in the adjacent liver }\end{array}$ \\
\hline $\begin{array}{l}\text { - Emphysematous } \\
\text { cholecystitis }\end{array}$ & $\begin{array}{l}\text { Similar findings to acute cholecystitis, with presence of gas in the gallbladder wall (intraluminal gas can be due to } \\
\text { fistula formation or other causes of pneumobilia) }\end{array}$ \\
\hline $\begin{array}{l}\text { - Perforated } \\
\text { cholecystitis }\end{array}$ & $\begin{array}{l}\text { Similar findings to acute cholecystitis, with focal defect in the gallbladder wall, contiguous pericholecystic fluid or } \\
\text { hepatic abscess }\end{array}$ \\
\hline - Gallstone ileus & $\begin{array}{l}\text { Small bowel obstruction with gallstone(s) at the point of transition, cholelithiasis (with varying degrees of inflammatory } \\
\text { changes around the gallbladder), possible presence of intraluminal gas in the gallbladder and pneumobilia }\end{array}$ \\
\hline $\begin{array}{l}\text { - Cholecystoenteric } \\
\text { fistula }\end{array}$ & $\begin{array}{l}\text { Cholelithiasis (with varying degrees of inflammatory changes around the gallbladder), contracted gallbladder with } \\
\text { luminal gas, a loop of bowel inseparable from the gallbladder wall }\end{array}$ \\
\hline - Mirizzi syndrome & $\begin{array}{l}\text { Dilated intrahepatic bile ducts with the common bile duct of normal calibre, large gallstone at the gallbladder neck } \\
\text { or cystic duct with varying degrees of inflammatory changes around the gallbladder }\end{array}$ \\
\hline
\end{tabular}

Table II. Checklist for identification of complications from cholecystitis.

\begin{tabular}{|c|c|}
\hline \multicolumn{2}{|l|}{ Gallbladder wall } \\
\hline - Thickness & $\geq 0.3 \mathrm{~cm}$ is considered thickened \\
\hline - Enhancement & Poor enhancement or irregular enhancement \\
\hline - Continuity & $\begin{array}{l}\text { Focal wall defect suggests gangrenous cholecystitis; focal defect with } \\
\text { contiguous pericholecystic fluid suggests perforated cholecystitis }\end{array}$ \\
\hline - Irregularity of wall & Irregularity is a sign of acute cholecystitis \\
\hline - Gas & Intramural gas is a sign of emphysematous cholecystitis \\
\hline \multicolumn{2}{|l|}{ Gallbladder lumen } \\
\hline - Gallstone & Usually at the gallbladder neck \\
\hline - Gas & Cholecystoenteric fistula with or without ileus \\
\hline - High-density fluid & Haemorrhagic fluid from gangrenous cholecystitis or gallbladder empyema \\
\hline - Sloughed mucosa & Considered as a specific sign of gangrenous cholecystitis \\
\hline \multicolumn{2}{|l|}{ Pericholecystic space } \\
\hline - Fluid & $\begin{array}{l}\text { Small amount is usually present in uncomplicated acute cholecystitis; } \\
\text { large amount is a red flag for gangrenous or perforated cholecystitis }\end{array}$ \\
\hline - Abscess & Pericholecystic abscess suggests gangrenous or perforated cholecystitis \\
\hline \multicolumn{2}{|l|}{ Liver, peritoneal cavity and bowel } \\
\hline - Reactive hyperaemia in adjacent liver & Sign of inflammation of the gallbladder (almost always seen) \\
\hline - Liver abscess & Small to huge, secondary to gallbladder perforation \\
\hline - Peritoneal collection & Large collection suggests perforated cholecystitis \\
\hline - Dilated small bowel & Presence suggests gallstone ileus \\
\hline
\end{tabular}

The severity of clinical presentation may not be representative of the underlying complications. Cross-sectional imaging is critical in identifying the complications associated with acute cholecystitis. Familiarity with the spectrum of relevant imaging features, as presented here, is imperative for the emergency radiology team.

\section{REFERENCES}

1. Kimura Y, Takada T, Kawarada Y, et al. Definitions, pathophysiology, and epidemiology of acute cholangitis and cholecystitis: Tokyo Guidelines. J Hepatobiliary Pancreat Surg 2007; 14:15-26.

2. Indar AA, Beckingham IJ. Acute cholecystitis. BMJ 2002; 325:639-43.

3. Byrne J, Berger RL. The pathogenesis of acute cholecystitis. Arch Surg 1960; 81:812-6.

4. Pinto A, Reginelli A, Cagini L, et al. Accuracy of ultrasonography in the diagnosis of acute calculous cholecystitis: review of the literature. Crit Ultrasound J 2013; 5:S11.
5. Ralls PW, Colletti PM, Lapin SA, et al. Real-time sonography in suspected acute cholecystitis. Prospective evaluation of primary and secondary signs. Radiology 1985; 155:767-71.

6. Fidler J, Paulson EK, Layfield L. CT evaluation of acute cholecystitis: findings and usefulness in diagnosis. AJR Am J Roentgenol 1996; 166:1085-8.

7. Paulson EK. Acute cholecystitis: CT findings. Semin Ultrasound CT MR 2000; 21:56-63.

8. Yamashita K, Jin MJ, Hirose Y, et al. CT finding of transient focal increased attenuation of the liver adjacent to the gallbladder in acute cholecystitis. AJR Am J Roentgenol 1995; 164:343-6.

9. Barakos JA, Ralls PW, Lapin SA, et al. Cholelithiasis: evaluation with CT. Radiology 1987; 162:415-8.

10. Van Breda Vriesman AC, Engelbrecht MR, Smithuis RH, Puylaert JB. Diffuse gallbladder wall thickening: differential diagnosis. AJR Am J Roentgenol 2007; 188:495-501.

11. Zissin R, Osadchy A, Gayer G, Kitay-Cohen Y. Extrarenal manifestations of severe acute pyelonephritis: CT findings in 21 cases. Emerg Radiol 2006; 13:73-7.

12. Fagan SP, Awad SS, Rahwan K, et al. Prognostic factors for the development 
of gangrenous cholecystitis. Am J Surg 2003; 186:481-5.

13. Bennett GL, Rusinek $H$, Lisi $V$, et al. CT findings in acute gangrenous cholecystitis. AJR Am J Roentgenol 2002; 178:275-81.

14. Morris BS, Balpande PR, Morani AC, et al. The CT appearances of gallbladder perforation. Br J Radiol 2007; 80:898-901.

15. Sunnapwar A, Raut AA, Nagar AM, Katre R. Emphysematous cholecystitis: Imaging findings in nine patients. Indian J Radiol Imaging 2011; 21:142-6.

16. Safioleas M, Stamatakos M, Safioleas P, et al. Mirizzi Syndrome: an unexpected problem of cholelithiasis. Our experience with 27 cases. Int Semin Surg Oncol 2008; 5:12.

17. Berland LL, Lawson TL, Stanley RJ. CT appearance of Mirizzi syndrome. J Comput Assist Tomogr 1984; 8:165-6.

18. Choi BW, Kim MJ, Chung JJ, et al. Radiologic findings of Mirizzi syndrome with emphasis on MRI. Yonsei Med I 2000; 41:144-6.

19. Masannat $Y$, Massanat $Y$, Shatnawei A. Gallstone ileus: a review. Mt Sinai J Med 2006; 73:1132-4.

20. Lassandro F, Romano S, Ragozzino A, et al. Role of helical CT in diagnosis of gallstone ileus and related conditions. AJR Am J Roentgenol 2005; 185:1159-65.

21. Rigler LG, Borman CN, Noble JF. Gallstone obstruction. Pathogenesis and roentgen manifestations. JAMA 1941; 117:1753-9.

22. Pickhardt PJ, Friedland JA, Hruza DS, Fisher AJ. Case report. CT, MR cholangiopancreatography, and endoscopy findings in Bouveret's syndrome. AJR Am J Roentgenol 2003; 180(4):1033-5.

23. LeBlanc KA, Barr LH, Rush BM. Spontaneous biliary enteric fistulas. South Med J 1983; 76:1249-52.

24. Stull JR, Thomford NR. Biliary intestinal fistula. Am J Surg 1970; 120:27-31. 


\section{SINGAPORE MEDICAL COUNCIL CATEGORY 3B CME PROGRAMME} (Code SMJ 201508B)

Question 1. The following have gallbladder wall thickening as an imaging feature:
(a) Acute cholecystitis.
(b) Hypoproteinaemia.
(c) Hepatitis.
(d) Ascites.

Question 2. The following indicate an increased risk of developing gangrenous cholecystitis:
(a) Elderly patients.
(b) Diabetes mellitus.
(c) White blood cell count $>15,000$ cells $/ \mathrm{mL}$.
(d) Chronic anaemia.

Question 3. The following computed tomography (CT) features suggest gangrenous cholecystitis:
(a) Poorly enhancing gallbladder wall.
(b) Curvilinear membranes in the gallbladder lumen.
(c) Intramural abscesses.
(d) Pericholecystic fat stranding.

Question 4. The following CT features suggest Mirizzi syndrome:

(a) Dilated intrahepatic ducts with nondilated common bile duct.

(b) Dilated common bile duct and normal intrahepatic ducts.

(c) Dilated pancreatic duct and common bile duct.

(d) Dilated intrahepatic and extrahepatic bile ducts.

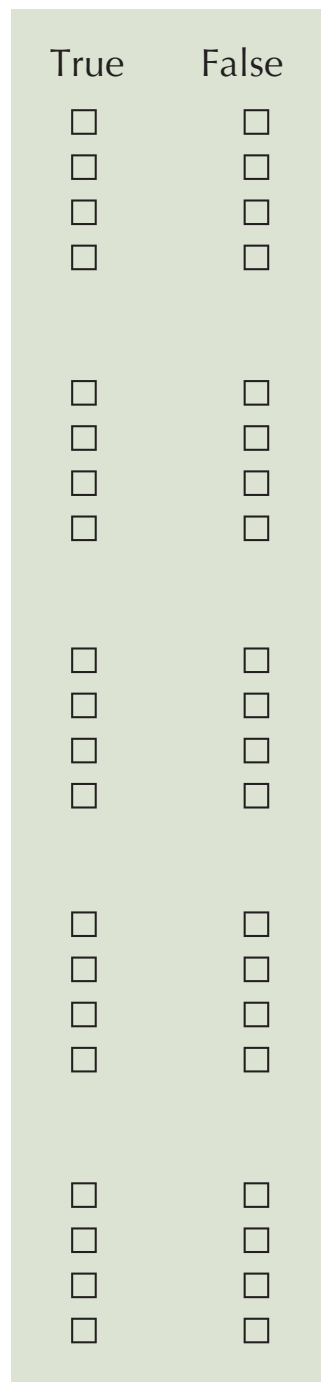

Question 5. Regarding gallstone ileus:
(a) Patients present with gastric outlet obstruction.
(b) Offending gallstones are usually less than $2 \mathrm{~cm}$.
(c) Rigler's triad can be seen on CT.
(d) Obstruction is usually at the level of the distal jejunum.

\footnotetext{
Doctor's particulars:

Name in full

MCR number

Email address

Specialty:

SUBMISSION INSTRUCTIONS:

(1) Log on at the SMJ website: http://www.sma.org.sg/publications/smjcurrentissue.aspx and select the appropriate set of questions. (2) Provide your name, email address and MCR number. (3) Select your answers and click "Submit".

RESULTS:

(1) Answers will be published in the SMJ October 2015 issue. (2) The MCR numbers of successful candidates will be posted online at the SMJ website by 2 October 2015. (3) Passing mark is $60 \%$. No mark will be deducted for incorrect answers. (4) The SMJ editorial office will submit the list of successful candidates to the Singapore Medical Council. (5) One CME point is awarded for successful candidates.

Deadline for submission: (August 2015 SMJ 3B CME programme): 12 noon, 25 September 2015.
} 